\title{
A Review on Student Satisfaction Research in the Area of Sino-foreign Cooperation in Running Schools or Education Programs
}

\author{
Yue-han $\mathrm{FU}^{1}$ and Li-ping $\mathrm{XIA}^{2, *}$ \\ ${ }^{1}$ Sino-U.S. Institute for University Design, Sichuan University, Chengdu, China \\ ${ }^{2}$ Intensive language Training Center / College of International Studies, Sichuan University, Chengdu, \\ China \\ ${ }^{*}$ Corresponding author
}

Keywords: Sino-foreign Cooperation in Running Schools or Education Programs, Student Satisfaction, Literature Review, Implications.

\begin{abstract}
Student satisfaction is increasingly becoming an important scale to evaluate and measure the education quality of Sino-foreign cooperation in running schools or education programs in recent years. This paper attempts to review the student satisfaction research in the area of Sino-foreign cooperation in running schools or education programs, based on papers published in CNKI. After examining 18 articles, the authors find that some achievements are made by domestic scholars, but domestic research in this field is still weak in terms of research contents, methodologies and constructive suggestions. The purpose of this paper is to provide valuable information and implication for researchers and practitioners in the relevant field.
\end{abstract}

\section{我国中外合作办学学生满意度研究述评}

\author{
付悦涵 ${ }^{1}$, 夏丽萍 $2,{ }^{*}$ \\ 1四川大学中美大学战略规划研究所, 成都, 中国 \\ 2 四川大学出国留学人员培训部/出国留学预备学院, 成都, 中国 \\ *通讯作者
}

关键词: 中外合作办学; 学生满意度; 研究述评; 启示

摘要：作为我国改革开放后教育领域出现的新事物, 中外合作办学经过近30年的发展，其规 模不断扩大, 其质量保障也成为中外合作办学研究者和实践者的关注重点。由于学生满意度 不仅是衡量中外合作办学项目成功的指标之一，也为中外合作办学质量保障建设提供参考依 据, 对中外合作办学学生满意度的研究近年来逐渐受到关注。本文从研究主体、研究方法、 研究内容和研究结果等方面对中外合作办学学生满意度研究进行梳理和分析, 旨在总结成就, 发现不足, 以期促进中外合作办学研究的更好发展。

\section{1. 背景}

“1978年改革开放之初, 我国实际上已经开始探索各种形式的中外合作办学活动。进入80 年代中期, 中国人民大学、复旦大学等高等院校相继举办了中美经济学、法学培训班。随后, 天津财经学院与美国俄克拉荷马市大学合作举办MBA班, 南京大学与美国霍普金斯大学合作 创建中美文化研究中心等, 这些机构均属早期中外合作办学的先例。”[1]

经过近30年的发展，我国中外合作办学规模初具，截止到2017年8月3日，我国本科中外 合作办学机构 70 个, 项目 930 个; 硕士及以上中外合作办学机构有 36 个, 项目达到了 219 个 ${ }^{[2] 。}$ 
中外合作办学布局也更加合理, 学科专业结构逐步优化, 进入快速、平稳和高质量的发展阶 段。

近年来, 随着我国中外合作办学进入提质增效的发展阶段, 学生满意度调查被不断运用 于中外合作办学机构或项目中，以便为中外合作办学质量保障建设提供依据。

本研究的样本来源于中国知识资源总库 (CNKI)。2018年1月18日，按照主题、篇名为“中 外合作办学学生满意度”、“中外合办作学教学满意度”和“中外合作办学项目满意度”的索检条 件和内容, 在中国知识资源总库 (CNKI) 索检到文献共45篇, 经过䇻选, 排除掉重合文献和 与主题无关的文献, 共得到有效样本文献18篇, 其中期刊14篇, 硕士学位论文4篇。根据18 篇有效样本文献, 本文从研究主体、研究方法、研究内容和研究结果等方面对中外合作办学 学生满意度研究进行梳理与分析, 旨在为中外合作办学研究者和实践者提供有价值的参考信 息和启示。

\section{2. 中外合作办学学生满意度研究的研究主体及方法}

从研究主体来看, 主要呈现以下特点: 第一, 研究者均来自高校, 其中一些研究者就职 于中外合作办学机构或项目; 第二, 大部分研究者都有从事中外合作办学相关的教学与管理 活动的经历, 说明对中外合作办学学生满意度的研究有其现实需要; 第三, 研究者层次参差 不齐, 有在校研究生, 也有高校的教师与管理工作者, 对该领域的研究尚未形成一定的学术 影响力, 尚未形成学术权威; 第四, 大部分研究者都有基金项目支持, 说明政府和高校支持 中外合作办学学生满意度的研究。

从研究方法来看, 主要呈现以下特点: 第一, 研究者都使用问卷调查法对学生满意度进 行测评。此外, 由于中外合作办学的特殊性, 研究者们在借鉴国内外学生满意度相关指标和 量表的基础上, 对于中外合作办学学生满意度调查指标、量表和调查问卷进行了创新。钟秉 林、周海涛和夏欢欢 (2012) 在PZB的SERVQUAL量表的基础上, 从服务管理、办学条件及 情感投入角度设计了学生满意度调查指标和量表, 并进行了抽样调查 ${ }^{[3]}$ 。刘扬、李晓燕、李 名义和孔繁盛（2016）在查阅国内外文献的基础上，借鉴英国NSS大学生满意度调查量表的 部分维度, 结合美国SSI量表的教学部分题项及其绩差测量方法, 又根据中外合作办学的特点, 构建了关于中外合作办学教学的学生满意度框架, 并编制了中外合作办学学生满意度量表和 问卷 ${ }^{[4]}$ 。第二, 运用多种研究方法相结合进行研究。姬冠(2013)在对湖南农业大学中外合作办 学模式下的双语教学进行调查时, 采用访谈与问卷调查相结合的方法 ${ }^{[5]}$ 。汤美玲和杨立军

（2015）在对 “南邮-纽约理工中外合作办学项目”的中外课程教师的教学模式和评价方式、学 生对于课程教学模式和评价方式的满意度以及学生的学习收获进行调查时, 采用了文献分析、 课堂观摩、问卷调查等研究方法 ${ }^{6]}$ 。第三, 对于问卷调查的结果, 研究者普遍采用了多种分 析方法, 主要分析方法为描述性分析、因子分析和单因素回归分析等。第四, 实证研究为主。 研究者通过问卷调查等方式收集资料, 并提出理论假设或检验理论假设而进行研究。

\section{3. 中外合作办学学生满意度研究的研究内容及结果}

对于中外合作办学学生满意度研究, 研究者们主要是以学生满意度理论为基础, 从学生 的视角对中外合作办学的各个方面进行调查, 研究内容及结果如下:

刘奕鸣（2007）在其硕士学位论文中, 针对我国中外合作办学的质量评价体系尚未真正 建立, 现行的一些评价方式因缺乏普遍适用性、灵活性, 而往往影响到合作项目运行中各类问 题的及时反馈和解决的现状, 在借鉴工商业领域的服务质量评价方式、结合教育领域的实际情 况和合作办学的特殊性的基础上, 提出了一套以教育服务质量为核心、以学生的满意度调查 为切入点、综合教师和教育管理人员的认知及建议的实用性评价模型, 并对 $S$ 大学 $C$ 学院中外 合作办学项目进行满意度调查, 得出影响高等教育服务质量的五大属性, 以及合作办学管理各 层面所涉及到的个具体指标项 ${ }^{[7]}$ 。 
陈恒 (2010) 以学习满意理论为切入点, 对 Z大学中德合作项目学生的学习满意情况进行 调查, 通过比较分析各项指标的满意度差异, 发现学生在德国校园学习总体满意度显著高于 在国内校园学习的满意度; 中德两个校园学习满意度还因性别、年级和专业差异, 并基于研 究发现, 提出了针对合作办学项目教学和管理的建议 ${ }^{[8]}$ 。

钟秉林、周海涛和夏欢欢 (2012) 在PZB的SERVQUAL量表的基础上, 从服务管理、办 学条件及情感投入角度设计了学生满意度调查指标和量表, 以3 个中外合作本科办学机构和 分布于12所高校的38 个本科以上中外合作办学项目的学生作为被试对象进行调查, 研究发现 学生对中外高等教育合作办学服务质量的重要性期望值与实际满意水平之间存在明显差异, 整体上为“不满意”; 不同性别、年龄、学历层次、学费水平的学生群体对服务质量的满意度 存在显著差异; 中外高等教育合作办学服务质量满意度与影响因子之间呈显著正相关关系 ${ }^{[3]}$ 。

姬冠（2013）通过调查湖南农业大学国际学院的学生对双语教学的满意度, 发现学生对 双语教学的需求迫切; 课程设置有待优化; 教材使用参次不齐; 教学效果不尽如人意, 学生 的满意度不高, 并基于研究发现提出如下建议: 激发热情, 改善环境, 是促进双语教学的前 提; 优化教材, 改革模式, 是促进双语教学的基础; 保障师资, 改进方法, 是促进双语教学 的关键; 政策支持, 有效管理, 是促进双语教学的保障 ${ }^{[5]}$ 。

李荷迪、朱苏永和谢颖峰 (2014) 以学生满意度理论为基础, 自行设计“中美合作办学学 生调查问卷”, 从学生基本情况、满意度总体评价、办学条件、教学质量、师资力量、管理效 能等方面对 $\mathrm{N}$ 大学中外合作办学项目的学生进行调查分析。研究发现课程设置、实验室条件、 教学模式、教材选用等因素较大程度上影响了学生对中外合作办学项目的总体满意度水平 ${ }^{[9]}$ 。

沈菲菲、周景芸和张松松（2014）通过在线问卷的方式分别调查了宁波诺丁汉大学和英 国诺丁汉大学中国学生在总体教育体验以及学习资源图书馆、教与学、学术支持、评估和反 馈、个人发展、职业发展6个维度的满意度情况, 并根据收集的数据比较分析中外合作办学的 宁波诺丁汉大学质量保障的不足之处并就如何改善提出相应行动建议, 以期为提高与完善我 国跨境高等教育中的中外合作办学教育质量提供借鉴 ${ }^{[10]}$ 。

汤美玲和杨立军 (2015) 系统比较“南邮-纽约理工中外合作办学项目”中外课程教师的教 学模式和评价方式、学生对于课程教学模式和评价方式的满意度以及学生的学习收获后, 发 现中外课程教学方法、课程考核评价方式存在显著差异; 学生的学习收获存在显著差异; 学 生对中外课程教学方法、课程考核评价总体满意度不存在显著差异, 但对具体的教学方法、 课程考核方式的满意度存在显著差异 ${ }^{[6]}$ 。

吴薇和罗俊艳（2016）通过对厦门某独立学院中外合作办学项目的学生进行教学质量及 其各个维度 (课程设计、师生互动、教学方法、教师能力、教学态度) 的满意度、对教学管 理的满意度的调查发现：学生在教学质量与教学管理的总体满意度方面表现为“一般”; 学生 对外籍教师在师生互动与教学方法上的满意度得分较高, 而对中国教师在课程设计、教师能 力与教学态度上的满意度得分较高; 不同年级的学生在教学质量的各个维度以及教学管理方 面存在着异同。并基于研究提出了相关建议 ${ }^{[11]}$ 。

刘扬、李晓燕、李名义和孔繁盛（2016）从学生满意度的视角, 参考国内外高等教育教 学质量评价指标, 设计了评价高校中外合作办学教学满意度的五维量表, 并通过抽样调查进 行了信效度检验。研究发现, 该量表具有较好的信效度; 学生对合作办学教学的期望值较高, 而对教学的满意度平均水平并不理想。基于此, 研究进行了各维度的分析, 并提出相关建议 [4]。

南娜（2016）在其硕士学位论文《基于学生满意度的中外合作大学教学质量评价一以 西交利物浦大学为例》中, 以西交利物浦大学为例, 在实证研究的基础上, 通过问卷调查的方 式搜集资料,并利用SPSS20.0统计软件对数据进行描述性统计、因子分析、独立样本T检验以 及树模型等方法分析该校学生对学校教学质量的满意度评价,力求为中外合作办学的良好发 展提出对策和建议 ${ }^{[12]}$ 。 
葛晓荵 (2017) 为了更好地挖掘中外合作办学项目办学模式和质量保障体系建设的内容, 对浙江财经大学中加会计合作项目的学生进行学习满意度调研, 以发掘影响中外合作办学项 目学生学习满意度的关键因素。研究发现了影响总体学习满意度的维度为: 课程设置、教师 教学、组织管理、个人发展和外教教学。而这些因子的影响作用, 又因为专业态度和学习目 标的差异而存在差异 ${ }^{[13]}$ 。

秦琼（2017）在其硕士学位论文中，在查阅大量关于“中外合作办学质量保障”和“中外合 作办学教学质量保障”的文本资料的基础上, 通过向安徽省本科层次合作办学项目的部分学生 发放调查问卷, 了解他们对就读项目内部教学质量保障要素的满意度, 以此为依据来审视这 些项目内部教学质量保障的状况。发现其存在的问题, 并进一步分析和揭示造成这些问题的 原因。据此, 提出安徽省高校中外合作办学内部教学质量保障的改进建议 ${ }^{[14]}$ 。

\section{4. 主要成就}

首先, 从研究内容来讲, 一方面, 研究者们从教学、管理和设施等多个维度进行中外合 作办学学生满意度的实证研究, 在一定程度上探测了我国中外合作办学学生满意度的真实情 况, 这为如何促进中外合作办学提质增效提供了可循路径。

其次, 从研究方法来讲, 一些实证研究较为规范, 增强了研究结果的有效性, 同时也为 以后的研究起到了示范作用。如: 刘扬、李晓燕、李名义和孔繁盛（2016）在对国内外学生 满意度文献进行梳理后, 又借鉴英国NSS大学生满意度调查量表的部分维度, 结合美国SSI量 表的教学部分题项及其绩差测量方法, 根据中外合作办学的特点, 构建了关于中外合作办学 教学的学生满意度框架, 并编制了中外合作办学学生满意度量表和问卷。

此外, 从研究结果来讲, 研究者发现, 中外合作办学机构和项目的在读学生对中外合作 办学充满期待, 但其实际满意度不尽人意。基于学生满意度反映的结果, 一些研究者提出了 对应的改进措施, 不仅为如何提升学生满意度提供了切入点, 也为中外合作办学质量提升提 供了思路。

\section{5. 研究不足}

研究内容不够丰富。研究者们主要是从教学、管理和设施等几个维度进行中外合作办学 学生满意度的实证研究, 还没有对中外合作办学学生满意度的理论、主要影响因素和内部结 构进行深入探析。

研究方法有待突破。研究者们虽然运用了文献研究法、问卷调查法、统计分析法和访谈 研究法等研究方法, 但是在进行实证研究时, 主要是借鉴国外高校学生满意度的指标体系, 而国内尚未形成一个统一的调查样本、测量指标的标准体系, 这在一定程度上可能影响研究 的信度和效度。

基于研究结果的对策建议不够具体, 适用性不强。部分研究者仅给出了研究结果, 没有 对研究结果进行分析。尽管有研究者基于研究结果提出了对应措施和办法, 但是不够具体, 适用性不强, 也没有进行可操作性的应用研究。

对中外合作办学学生满意度的关注还不够。学生满意度调查是当今世界各国大学尤其是 发达国家大学 “生校关系”管理方面的主要工具 ${ }^{[8]}$ 。我国高校的学生满意度调查始于2001年, 现在已经被广泛开展于高校中，但在中外合作办学研究方面应用还比较少。

\section{6. 小结}

近年来, 国内对中外合作办学学生满意度的研究虽然取得了一定的成就, 但由于我国学 生满意度研究起步晚, 仍存在研究关注度不够、研究内容不够丰富、研究方法待突破等问题, 因此, 对中外合作办学学生满意度的研究还需要进一步加强, 通过学生满意度研究, 为中外 合作办学的师资建设、教学质量和管理质量的提升提供有意义的参考依据和对策建议。 


\section{References}

[1] G. Z. Jiao, Review and reflection on Sino-foreign cooperation in running schools, China Higher Education. 10 (1998) 42-44.

[2] Information on http:/www.jsj.edu.cn

[3] B. L. Zhong, H. T. Zhou, H. H. Xia. The study of students service quality satisfaction in China-foreign cooperation institutions, China Higher Education Research. 9 (2012) 22-26.

[4] Y. Liu, X.Y. Li, M. Y. Li, Fan-sing Hung. A study on the instructional satisfaction assessment for Chinese-foreign cooperation in running schools at university level, Fudan Education Forum. 4 (2016) 43-61.

[5] G. Ji, Bilingual teaching of Sino-foreign cooperation in running schools -- based on the investigation of Hunan Agricultural University, Higher Agricultural Education. 10 (2013) 74-76.

[6] M. L. Tang, L.J. Yang, An empirical study on differences in teaching and learning between Chinese and foreign courses: the case of NYIT-NUPT joint-degree programs, Fudan Education Forum. 1 (2015) 30-36.

[7] Y. M. Liu, Study on the evaluation of service quality of joint education in college, Shanghai, 2007, pp. 1-105.

[8] H. Chen, A comparative analysis on students' satisfaction of Sino-foreign cooperation in running schools -- taking Sino-german " $2+3$ " cooperative joint programme in Z University as an example, Education Research Monthly. 8 (2010) 20-23.

[9] D. H. Li, S.Y. Zhu, Y. F. Xie, Investigation and analysis on students' satisfaction of Chinese-foreign cooperation in running schools -- taking Sino-US “2 + 2" cooperative joint programme in $\mathrm{N}$ university as an example, Journal of Ningbo Radio TV University. 1 (2014) 100-103.

[10]F. F. Shen, J. Y. Zhou, S. S. Zhang, Quality assurance of cross-border higher education in China: a case study based on a survey of student satisfaction, Journal of Yangzhou University (Higher Education Study Edition). 3 (2014)15-21.

[11]W. Wu, J. Y. Luo, A study on undergraduates' satisfaction with Chinese-foreign cooperative program of independent college, Research in Higher Education of Engineering. 1 (2016) 82-86.

[12] N. Nan, The teaching quality evaluation of Sino-foreign cooperative university based on student satisfaction- Xi'an Jiaotong-Liverpool University Case, Suzhou, 2016, pp. 1-75.

[13]X. R. Ge, A study on the students' Satisfaction Assessment for Sino-foreign cooperation in running schools - taking Sino-foreign cooperative joint programme in Zhejiang University of Finance \& Economics as an example, Commercial Accounting. 5 (2017) 107-111.

[14]Q. Qin, The research on the internal teaching quality assurance of sino-foreign cooperative education in the university of Anhui province -- taking the cooperative education program of undergraduate as an example. Anhui, 2017, pp. 1-79. 